\title{
The Possibility of Complex Treatment of Optic Nerve Atrophy based on Etiopathogenetic Approach using the New Classification of this Ophthalmopathology
}

\author{
A I Bereznikov* \\ Department of Ophthalmology, Kursk State Medical University, Russia
}

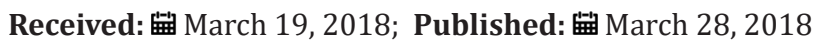

*Corresponding author: AI Bereznikov, Department of Ophthalmology, Kursk State Medical University, Kursk, ul K Marks 3, Russia, Email: abereznikov@rambler.ru

\section{Abstract}

Application of treatment, differentiated based on the degree of functional changes and stages of atrophy, type of atrophy and nature of the lesion, significantly alters the effectiveness of treatment when compared to the isolated electropharmocological stimulation and even more so compared to the traditional medication method of treatment.

Keywords: New clinical classification and treatment of optic nerve atrophy

Abbreviations: ONA: Optic Nerve Atrophy; PONA: Partial Optic Nerve Atrophy

\section{Introduction}

Optic nerve atrophy (ONA) is the end result of disease, intoxication, genetically determined abnormality or injury of retinal ganglion cells and/or their axons situated between the retina and the lateral geniculate bodies of the brain. The prevalence percentage of various optic nerve diseases in the eye disease hospital is approximately $1-1.5 \%, 19$ to $26 \%$ of those cases resulting in complete atrophy of the optic nerve and incurable blindness. Causes of ONA are: diseases of retina and optic nerve (inflammation, dystrophy, including glaucomatic and involutional,

Table 1: Clinical Classification of the Partial Optic Nerve Atrophy. poor circulation due to hypertension, atherosclerosis, diabetes, etc., swelling, profuse bleeding, compression and damage of the optic nerve), diseases and injuries of the orbit, Central nervous system diseases (optic-chiasm leptomeningitis, abscesses and brain tumors with increased intracranial pressure, neurosyphilis, demyelinating disease, traumatic brain injury), intoxication with methyl alcohol, antibiotics (streptomycin, gentamicin), antimalarial drugs (quinine, hingamin). ONA may be a component or sole manifestation of a number of hereditary diseases (congenital amaurosis, hereditary optic nerve atrophy, etc.) [1,2].

\begin{tabular}{|c|c|c|c|c|c|}
\hline \multirow{2}{*}{ Period } & \multirow{2}{*}{ Type } & \multirow{2}{*}{ Lesion class } & \multicolumn{2}{|r|}{ Stages } & \multirow{2}{*}{$\begin{array}{l}\text { Visual Functions } \\
\text { Dynamics }\end{array}$} \\
\hline & & & vis & Field of vision & \\
\hline \multirow{4}{*}{ Early Late } & Vascular & \multirow{4}{*}{$\begin{array}{c}\text { Peripheral } \\
\text { Central } \\
\text { Total }\end{array}$} & I $1,0-0,4$ & $\begin{array}{l}\text { Narrows by } 15-200 \text { the possibility of central relative } \\
\text { scotoma }\end{array}$ & Stabilized \\
\hline & Traumatic & & II $0,4-0,1$ & Narrows by 20 - 300 central periferal scotoma & Not stabilized \\
\hline & Toxic & & $\begin{array}{c}\text { III } 0,1- \\
0,001\end{array}$ & Concentric narrowing to up to 100 & \\
\hline & $\begin{array}{l}\text { Compressive } \\
\text { Congenital } \\
\text { Undetermined }\end{array}$ & & IV0,01 и < & Residual fields in the form of fragments & \\
\hline
\end{tabular}


Treatment of optic nerve atrophy is a very complex and difficult problem because of the extremely limited regenerative ability of the neural tissue. All depends on how widespread the degenerative process in the nerve fibers is and whether their viability is preserved. Some progress in the treatment of optic nerve atrophy has been achieved with the help of pathogenetically directed influences aimed to improve the viability of nervous tissue. The development of new methods of treatment of partial optic nerve atrophy (PONA) has greatly enhanced the possibility of rehabilitation of patients with this pathology. However, the abundance of methods in the absence of clear indications complicates the choice of a treatment plan in each individual case. $[1,3,4,5,6,7]$ The analysis of literature on diagnosis and treatment of PONA showed lack of clear classification and the existence of various approaches to the assessment of the severity of the disease[2,8,9,10]. The following classification presented in Table 1 was used to determine the treatment plan $[7,9]$. The purpose of work. To create a method of optic nerve atrophy treatment differentiated depending on severity and other individual characteristics of the patient and to analyze the effect of the application of this technique.

\section{Material and Methods}

To treat the patients with partial atrophy of the optic nerve, we use the following methods. Infita-a low-frequency pulse physiotherapy device designed to expose the central nervous system (CNS) to low-frequency pulse electromagnetic field (without direct contact with the patient), which results in an improved central blood flow, saturation of blood with oxygen, and increased redox processes in the nervous tissue. It has as the following characteristics: no output signal - a triangular voltage pulse with negative polarity, pulse frequency $20-80 \mathrm{~Hz}$ (most frequently used $40-60 \mathrm{~Hz}$ ), pulse duration of $3 \pm 2 \mathrm{~V}$, recommended number of procedures 12 - 15, starting with 5 minutes, increasing to 10 and then 12 minutes beginning with the fifth procedure and so on up to 12 treatments. Treatment method, hereinafter called the direct electropharmacological stimulation (EPS), includes installation of a soft PVC catheter into the retrobulbar space and a repeated inoculation of various medications through it into the retrobulbar space selected based on the etiopathogenesis of the atrophy. All patients were infused with a $10 \%$ solution of piracetam and exposed to electrical stimulation through a needle electrode inserted into the retrobulbar space through the catheter with the device "AMPLIPULS" 40 minutes later $[11,12]$.

Also the following surgical methods can be used -ligation of the superficial temporal artery, implantation of a collagen sponge into the subtenon space, decompression of the optic nerve. In connection with the specifics of performing of surgical procedures in our clinic the technique of their execution is given below. Ligation of the superficial temporal artery. Local anesthesia - lidocaine $2.0 \%$ subcutaneously. A $3 \mathrm{~cm}$ long skin incision is made $1 \mathrm{~cm}$ in front of the tragus. The tissue is bluntly separated. The superficial temporal artery is ligated with two stitches and overlaps between them. Albucidum powder is infused into the wound. The soft tissue is sutured with catgut suture. Silk sutures are placed on the skin. The wound is treated with a solution of brilliant green dye, aseptic sticker is placed. Implantation of a collagen sponge into the subtenon space. Local anesthesia - lidocaine 2,0 \% subcutaneously and dicain 0,5 epibulbarly. A 5-6 mm long skin incision is made in the upper nasal quadrant 5-6 $\mathrm{mm}$ away from the limbus, parallel to the limbus. A tunnel is formed between the sclera and the capsule of tenon to the posterior pole using a spatula. An implant of a collagen sponge $10-8 \mathrm{~mm}$ long and $5-6 \mathrm{~mm}$ wide, pre-soaked with the solution of emoxipine (cortexin, retinalamin and other drugs or their combinations) is implanted into the tunnel closer to the optic nerve. The suture is placed on the conjunctiva and under the conjunctiva, followed by antibiotics and dexamethasone. After the implantation, antibiotics and a solution of diclofenac is applied locally for 5 - 7 days $[13,14]$.

Decompression of the optic nerve is performed under general anesthesia. Blepharostat is used. An incision is made on the inner side of the conjunctiva. The internal straight muscle is sutured up in front the tendon and is clipped off. Three incisions of the scleral ring around the optic nerve are made. The solution of albucid is applied, and the muscle is locked in place. The suture is placed on the conjunctiva. Dixon and antibiotics are placed under the conjunctiva. The following scheme of treatment was suggested for the peripheral section of the optic nerve:

i. Degree: Emoksipin + dexamethasone subcutaneously in the region of the mastoid process, mildronat + emoxipin subcutaneously in the temple region, vitamin B1 1,0, alternate vitamin B6 $1.0 \mathrm{~V} / \mathrm{m}$ with piracetam $5.0 \mathrm{~V} / \mathrm{m}$, low-frequency electromagnetic stimulation.

ii. Degree: Catheterization of the retrobulbar space, direct EPS + long-term melioration: dexamethasone + emoksipin 2 times, piracetam (or other schemes depending on etiology), implantation of a collagen sponge with emoxipin into the subtenon space (ICS), piracetam 20,0 intravenously with physiological saline 200,0.

iii. Degree: Catheterization of the retrobulbar space, direct EFS + piracetam, dexamethasone, emoksipin 2 times a day. Implantation of a collagen sponge with emoxipin into the subtenon space, ligation of the superficial temporal artery, piracetam 20,0 intravenously with physiological saline 200,0.

iv. Degree: Step 1 - decompression of the optic nerve, step 2 or in case step 1 is not possible (severe somatic pathology) - catheterization + direct EFS, piracetam, dexamethasone, emoksipin 2 times retrobulbarly into the catheter. Ligation of the superficial temporal artery (if not done earlier). Implantation of a collagen sponge with emoxipin into the subtenon space, fenotropil tablets according to the treatment scheme, piracetam 20,0 intravenously with physiological saline 200,0 . 
Treatment scheme for the lesion of the central part of the visual pathway.

a. Stage I: Glycine 1 tablet 3 times a day sublingually for one month, cavinton according to the treatment scheme, then phenotropil (tablets) according to the treatment scheme. "Infita" - percutaneous low-frequency electrical stimulation.

b. Stage II: Cortexin intramuscularly No. 10. Trental intravenously in a physiological saline No. 5 (or aminophylline). Cerebrolysin intravenously No. 5. Glycine 1 tablet 3 times a day for one month. "Infita" low-frequency electrical stimulation.

c. Stage III: Cortexin intramuscularly No. 10. Glycine sublingually 1 tablet 3 times a day for one month. Trental intravenously in a physiological saline No. 5 (or aminophylline). Cerebrolysin or actovegin intravenously No. 5. Piracetam 5,0 intramuscularly No. 10. Antiplatelet agents (aspirin, clopidogrel) if necessary."Infita" - percutaneous low-frequency electrical stimulation.

d. Stage IV: Cortexin intramuscularly No. 10.Emoxipin intramuscularly No.10. Trental intravenously No. 5. Cerebrolysin or actovegin or solkoseril No. 10 Piracetam 5,0 intramuscularly No. 10. Antiplatelet agents (aspirin, clopidogrel) if necessary. Catheterization with direct EPS, dexamethasone, piracetam, emoksipin retrobulbarly into the catheter.

In case of total lesion of the visual pathway the elements of both treatment schemes of the corresponding stages are combined. To compare the effectiveness of different PONA treatment schemes three groups of patients were formed. The first group consisted of

Table 2: Results of treating patients with partial atrophy of the optic nerve.

\begin{tabular}{|c|c|c|c|c|c|}
\hline \multirow{2}{*}{ Type of Treatment } & \multirow{2}{*}{ Number of eyes treated } & \multicolumn{3}{|c|}{ Result } \\
\cline { 3 - 6 } & & \multicolumn{2}{|c|}{ Improvement } & \multicolumn{2}{c|}{ No change } \\
\cline { 3 - 6 } & & Number of eyes treated & $\%$ & Number of eyes treated & 168 \\
\hline Differentiated treatment & 508 & 340 & 66,9 & 68 \\
\hline Isolated direct EPS & 152 & 84 & 41 & 44,7 \\
\hline Medication therapy & 126 & 52 & 59 \\
\hline
\end{tabular}

Table 3: Results of treating patients with partial atrophy of the optic nerve.

\begin{tabular}{|c|c|c|c|c|c|}
\hline \multirow{3}{*}{ Type of Treatment } & \multirow{3}{*}{$\begin{array}{c}\text { Number of eyes } \\
\text { treated }\end{array}$} & \multicolumn{4}{|c|}{ Result } \\
\hline & & \multicolumn{2}{|c|}{ Visual acuity } & \multicolumn{2}{|c|}{ Field of vision } \\
\hline & & Before treatment & After treatment & Before treatment & After treatment \\
\hline $\begin{array}{l}\text { Differentiated } \\
\text { treatment }\end{array}$ & 508 & $0,35 \pm 0,06$ & $0,5 \pm 0,04$ & $271 \pm 16,4$ & $376 \pm 15$ \\
\hline Isolated direct EPS & 152 & s0,28 $\pm 0,04$ & $0,43 \pm 0.05$ & $245 \pm 14,8$ & $348 \pm 12,5$ \\
\hline Medication therapy & 126 & $0,32 \pm 0,05$ & $0,39 \pm 0,04$ & $266 \pm 15,6$ & $336,8 \pm 11,7$ \\
\hline
\end{tabular}

Note: $\mathrm{p}<0.01$, compared to the values before treatment.

No cases of deterioration were recorded.

\section{Conclusion}

Medication therapy combining medications which have various effects on the nervous tissue is effective only for the initial
358 patients (508 eyes) with optic atrophy of various etiology and pathogenesis, getting treatment, differentiated based on the stage, localization and duration of existence of atrophy. The second group consisted of patients who, regardless of the stage of atrophy, were subjected to a course of electropharmacological stimulation: 107 patients (152 eyes). The control group consisted of 77 patients (126 eyes) who received only medication treatment. The percentage composition of the main types of dystrophy in all three groups was similar.

The main study group consisted of 136 glaucoma patients (183 eyes), 81 patients (122 eyes) with the atrophy of vascular origin, post-inflammatory atrophy was observed in 51 (76 eyes), cerebral in 25 patients (50 eyes), traumatic 52 patients ( 52 eyes), toxic in 13 patients ( 25 eyes). The second group included 36 patients with glaucoma (46 eyes), 14 patients (38 eyes) with the atrophy of vascular origin, post-inflammatory atrophy was observed in 16 (24 eyes), cerebral in 5 patients (10 eyes), traumatic in 18 patients (18 eyes), toxic in 8 patients (16 eyes). The control group consisted of 24 patients with glaucoma (42 eyes), 21 patients (32 eyes) with the atrophy of vascular origin, post-inflammatory atrophy was observed in 14 people (22 eyes), cerebral in 3 patients ( 6 eyes), traumatic in 8 patients (10 eyes), and toxic in 7 patients (14 eyes). Patients of this group were treated in a conservative manner: emoxipin with mildronate subcutaneously in the temple region, emoksipin with dexamethasone subcutaneously in the area of the mastoid process, taufon under the conjunctiva, piracetam intramuscularly. The result of the treatment of patients with partial atrophy of the optic nerve depending on the type of treatment can be seen in Tables $2 \& 3$. 
advanced stages, and surgical methods - for severe cases. The use of treatment, differentiated based on the degree of functional changes, the type of atrophy and the nature of the lesion, significantly increases the effectiveness of treatment compared to the isolated use of EPS and even more so compared to medical treatment.

\section{References}

1. Libman ES, Shakhova EV (2000) State and dynamics of blindness and disability due to eye pathology in Russia. Congress of ophthalmologists of Russia, $7^{\text {th }}$ proc, Dokl-M-S, pp. 209-214.

2. Tron EZ (1968) Diseases of the visual pathways.

3. Baranov VI (2008) Dynamic monitoring of visual functions in the treatment of partial atrophy of the optic nerve by the method of direct electro pharmacological stimulation. The conference materials, Moscow, Russia.

4. Baranov VI, Bereznikov AI, Prusakova OY (2008) Collection of scientific articles VII all-Russian scientific-practical conference with international participation. The conference materials, Moscow, Russia, pp. 253-257.

5. Libman ES (1994) Conceptual approaches and the need for rehabilitation of disabled persons with a visual disability. Congress of ophthalmologists of Russia, $6^{\text {th }}-\mathrm{M}$, pp. 346.

6. Maichuk YF (2000) The global initiative for the elimination of preventable blindness in the world. Vestn Ophthalmology 4: 45-46.

7. Filipenko NG, Bereznikov AI (2012) Differentiated therapy of the partial atrophy of the optic nerve based on the etiopathogenetic approach using the new classification. Scientific statements of Belgorod state University, (17/1 ${ }^{\text {th }}$ edn), 4(123): $32-38$.

8. Katsnelson LA, Farafonova TI, Bunin IA (1990) Vascular diseases of the eye. M Medicine, P. 47-63.

9. Bereznikov AI (2015) The use of the device "Amplipuls" in the treatment of partial atrophy of the optic nerve of traumatic origin. Biomedical engineering 49(1): 45-47.

10. Sidorova SA, VB Laskova VB, Bobyntsev II (2011) Research on the neuroprotective activity of deltaran and effectiveness of coupled multichannel electroneurostimulation during the recovery period of ischemic stroke. Man and his health. Kursk scientific practical journal 1: 89-95.

11. Linnik LF, Anisimov SI (1994) Classification of partial atrophy of the optic nerve. Anisimov Ophthalmosurgery 4(S): 14-17.

12. Bereznikov AI (2007) Analysis of the use of long-term melioration of the retrobulbar space in combination with direct electrical stimulation in the treatment of diseases of the optic nerve. II Central-Asian conference on ophthalmology, The proceedings of the conference Issyk Kul, pp. 214217.

13. Linnik LF (1993) Recovery of visual functions in patients with partial optic nerve atrophy after a neuroinfection by method of electro. Ophthalmosurgery 1: 47-54.

14. Fedorov SN (1989) Functional parameters of electrical stimulation of the optic nerve during its partial atrophy as a result of circulatory collapse. Ophthalmosurgery 3(4): 3-8.

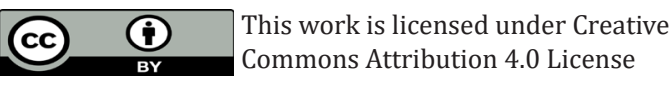

To Submit Your Article Click Here:

Submit Article
DOI: 10.32474 /OAJBEB.2018.02.000127

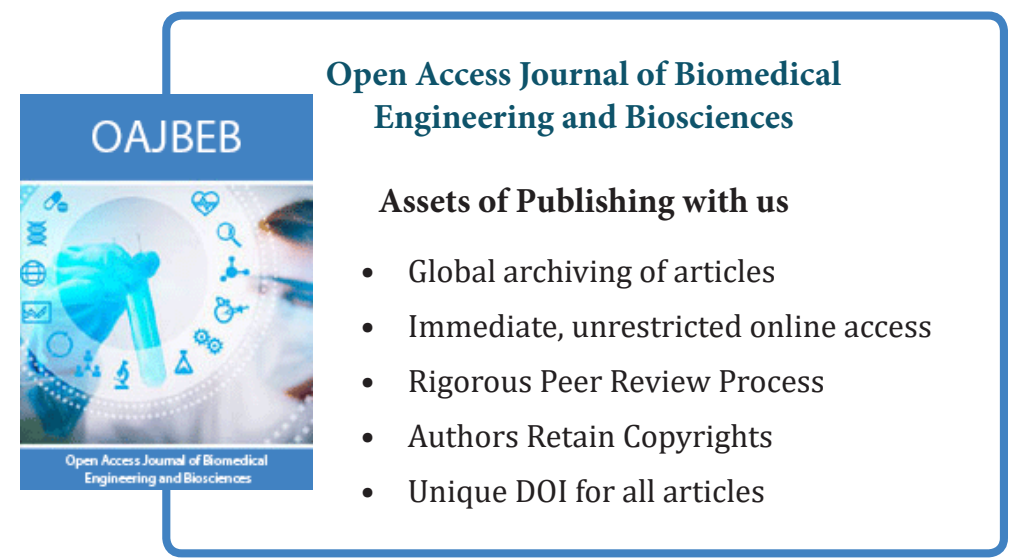

